Check for updates

Cite this: RSC Adv., 2017, 7, 22964

\title{
Systematic study of the crystallization process of CrAPO-5 using in situ high resolution X-ray diffraction
}

\author{
Pei Sheng, ${ }^{\text {ab }}$ Guofu Wang, ${ }^{a}$ Mei Dong, ${ }^{\text {a }}$ Gang Chen, ${ }^{\text {ab }}$ Huanhuan Yang, ${ }^{\text {ab }}$ \\ Weibin Fan, (D) ${ }^{a}$ Zhangfeng Qin $^{a}$ and Jianguo Wang ${ }^{a}$
}

Chromium substituted nano-porous aluminophosphate (CrAPO-5) was investigated to discuss the effect of $\mathrm{Cr}^{3+}$ ions on the crystallization kinetics and crystal structure parameters by in situ time-resolved high resolution X-ray powder diffraction (HRXRPD). Results showed that the introduction of $\mathrm{Cr}^{3+}$ into pure $\mathrm{AlPO}_{4}-5$ influenced both the crystallization velocity and structural parameters of the resultant AFI. The presence of $\mathrm{Cr}^{3+}$ ions can severely retard the crystallization of AFI. The more $\mathrm{Cr}^{3+}$ ions in the gels, the stronger inhibitory effect would be. A kinetic analysis of the crystallization of CrAPO-5 was performed. A fair linear relationship between the activation energy and $\mathrm{Cr}^{3+}$ content was concluded. The calculated Avrami exponent $n$ was in the range of 1-1.4, implying a similar 1D growth mechanism to that of AlPO $4-5$. The extracted structural parameters showed obvious crystal expansion, which might be caused by the trapping of $\mathrm{Cr}^{3+}$ ions in the framework. However, this influence on the structural parameters was limited. The $a(=b)$ parameters increased to a maximum with chromium content, which is similar to the influence on the crystal growing velocity. The grain size variation of AFI differed from other metal substituted aluminophosphate molecular sieves, which implied a different state of chromium in the $\mathrm{AlPO}_{4}-5$ framework. The time-resolved HRXRPD proves to be a direct and efficient method to reveal the influence of $\mathrm{Cr}^{3+}$ ions on the crystallization and shows indirect evidence on the state of $\mathrm{Cr}^{3+}$ in the crystalized CrAPO-5.

Received 22nd December 2016 Accepted 13th April 2017

DOI: 10.1039/c6ra28572d

rsc.li/rsc-advances or ion-exchange ability as the parent framework is neutral. However, if the product exhibits a compositional heterogeneity with evenly distributed chromium centers, it influences the sorption properties of the material in a similar way as charged centers in other metal substituted $\mathrm{AlPO}_{4}-5$. These sorption centers are able to interact with molecules adsorbed in the pores and act as a catalyst for reactions such as the oxidation of secondary alcohols and hydrocarbons in the liquid phase. ${ }^{9-13}$ Therefore, it is highly important to understand the crystallization mechanisms taking place during hydrothermal synthesis of aluminophosphate molecular sieves and metal-substituted ones, which will shed light on rational design and synthesis of new molecular sieves with specific crystalline structure, morphology and particle size for catalytic applications.

One problem generally overlooked in developing new catalytic system is the stability and heterogeneity of these materials under working conditions. $\mathrm{Cr}^{3+}$ in inorganic compounds exhibits a strong tendency to adapt octahedral coordination due to existence of stable trivalent ion and its $3 \mathrm{~d}^{3}$ ground state which splits into three stabilizing and two destabilizing orbitals in an octahedral field. Substitution for $\mathrm{Al}^{3+}$ is consequently a difficult task as it requires tetrahedral coordination of chromium. On the other hand, the present methods used to investigate state of $\mathrm{Cr}$ ions heavily rely on ultraviolet/visible spectroscopy (UV-vis), ${ }^{14-16}$ 
Raman spectroscopy ${ }^{17}$ electron paramagnetic resonance (EPR), ${ }^{15,18-24}$ X-ray absorption spectroscopy (XAS) ${ }^{25-27}$ and nuclear magnetic resonance (NMR), ${ }^{28}$ which all focused on the synthesized products. A large number of studies have been devoted to studying the transformation of gel to nanoporous materials using a variety of in situ techniques, like X-ray diffraction (XRD) methods, ${ }^{29-35}$ small-angle X-ray scattering (SAXS) techniques ${ }^{5}$ and X-ray absorption spectroscopy (XAS). ${ }^{36,37}$ Although a combined technique approach using all these methods has been reported to derive mechanistic aspects of the crystallization process, ${ }^{5,37}$ recent developments, particularly in the area of angular-dispersive high resolution powder X-ray powder diffraction (HRXRPD), make it possible to collect high-quality diffraction data in a very short time scale, which will not only determine the kinetics, but also the precise structural parameters, in particular the variation in lattice parameters of the reacting system. The in situ methods had been widely used on $\mathrm{Co}, \mathrm{Zn}$ and $\mathrm{Mn}$ substituted aluminophosphate molecular sieves. ${ }^{5,32-34,36-41}$ However, there is no report so far on the in situ study of the crystallization process of CrAPO-5. We present here an in situ study of the hydrothermal crystallization of CrAPO-5 starting from the precursor gel prepared with the classical method to the crystalline material using the high resolution synchrotron powder X-ray diffraction (HRXRD). This approach allowed us to achieve a deep understanding of the influence of $\mathrm{Cr}$ ions on the crystallization process of CrAPO-5, to study the kinetics, to extract the structural parameters and to investigate the state of $\mathrm{Cr}$ ions in $\mathrm{AlPO}_{4}-5$ frameworks during the synthesis process.

\section{Experimental methods}

\subsection{Sample preparation}

The AlPOs gels were prepared by a traditional method reported elsewhere. ${ }^{7}$ About $80-100 \mathrm{~mL}$ of each gel was prepared, sufficiently large for all synthesis and diffraction experiments performed. The following procedure was applied in the preparation of the gels: $\mathrm{H}_{3} \mathrm{PO}_{4}$ was first dissolved in water, followed by the addition of the transition metal ion salts. Then pseudoboehmite was added to the solution under vigorously stirring after the transition metal salts were fully dissolved. Finally, after stirring for at least $60 \mathrm{~min}$, triethylamine as templating molecule was introduced into the above mixture drop by drop under vigorous stirring. This mixture was further stirred for at least $2 \mathrm{~h}$. The charges were stored at room temperature in polyethylene vials. The APO-gel was prepared with a similar procedure. Preliminary crystallization experiments were conducted at
$200{ }^{\circ} \mathrm{C}$ in Teflon-lined autoclaves, and the obtained crystalline reaction products were identified from their X-ray powder patterns. ${ }^{42}$ The elemental composition analyzed by ICP were listed in Table 1.

No chemical analysis of the reaction products were performed, but a general composition can be given as

$$
\mathrm{Cr}_{1-m} \mathrm{AlPO}_{4} \cdot 1.0 \mathrm{TEA} \cdot 40 \mathrm{H}_{2} \mathrm{O}
$$

where $m$ refers to the molar ratio of $\mathrm{Cr}$ to $\mathrm{P}$. The obtained samples and gels were termed as $\mathrm{CrAPO}-5(m)$.

\subsection{In situ measurements}

A homemade device as shown in our previous work $^{43}$ was designed to meet the demands of in situ XRD analysis. In the in situ experiments, two heating modes were used: (i) heating of the gels from $c a .28$ to $200{ }^{\circ} \mathrm{C}$ in $90 \mathrm{~min}$ at a constant heating rate (temperature ramp) and (ii) heating of the gels in $1 \mathrm{~min}$ from $c a$. $28^{\circ} \mathrm{C}$ to a temperature between 140 and $170{ }^{\circ} \mathrm{C}$ and keeping the temperature for a certain period of time (isothermal). The in situ set-up and its detailed operation were described in our early work..$^{43}$ Four kind of gels with different $\mathrm{Cr}^{3+}$ content were studied using synchrotron radiation, as shown in Table 1.

The in situ XRD experiment was performed on the 4B9A beamline of BSRF at a fixed wavelength of $1.54 \AA$ with MYTHEN as the detector. The superiority of the MYTHEN detector used in the powder diffraction had been summarized and verified in some studies. ${ }^{44-46}$ The detailed information about the MYTHEN detector in BSRF was described by Du. ${ }^{45}$ Considering the signalto-noise ratio of the spectra and the reaction speed, the duration of each data collection was optimized to 60 to 120 seconds to cover a 2-theta range of $120^{\circ}$. In fact, only the data in the range of 5 to 40 degrees was effective to extract the useful information. The data was processed using Jade 6.5 software to extract the lattice parameter of the crystallizing system as a function of time. The kinetic information was extracted using the Avrami equation. The structural parameters were calculated using the Debye-Scherrer equation.

\section{Results and discussion}

\subsection{In situ XRD}

3.1.1 Temperature ramp. Systems of $\mathrm{AlPO}_{4}-5$ and CrAPO$5(m)(m=0.01,0.05,0.08)$ were studied under temperature programmed condition. None of the four investigated gels

Table 1 Chemical composition of the as-synthesized samples and the corresponding gels

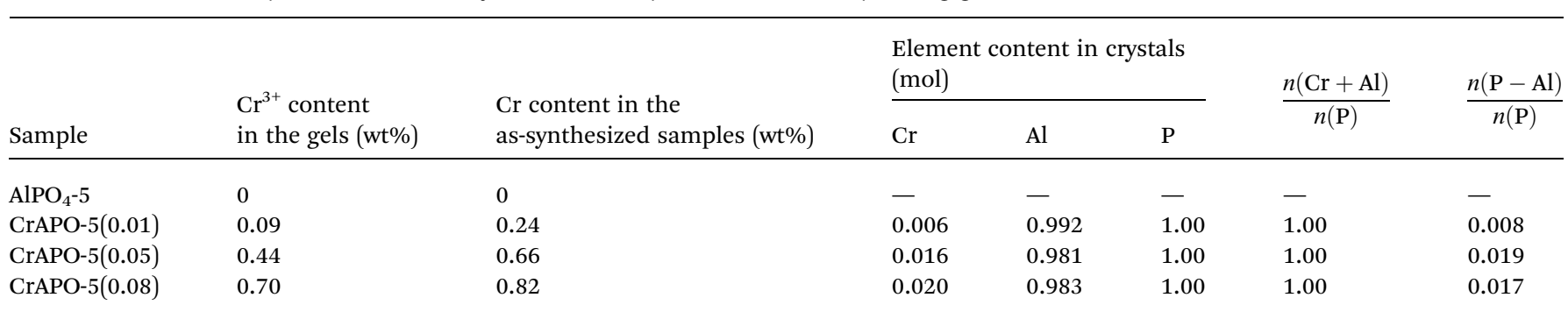


showed formation of crystalline precursor phases before the formation of the $[\mathrm{AFI}]$ type crystalline products. It is clear from the stacked plots that only pure AFI phase is formed in the experiments, irrespective of the metal content. Fig. 1a and b displayed the powder patterns obtained during the in situ experiments when the gel $\mathrm{AlPO}_{4}-5$ and CrAPO-5(0.05) was heated from 28 to $200{ }^{\circ} \mathrm{C}$. The peak intensity fluctuation can be ascribed to the instability of the input beam intensity and the intensity of the peaks were not normalized. The crystallization of the AlPO-gel starts at approximately $145^{\circ} \mathrm{C}$, while the gel of CrAPO-5(0.05) starts at approximately $150{ }^{\circ} \mathrm{C}$. The temperature is close to that of MnAPO-5, ${ }^{39}$ but is lower than that of CoAPO-5. ${ }^{5}$ That means the introduction of $\mathrm{Cr}^{3+}$ ions into the $\mathrm{AlPO}_{4}-5$ gels slowed down the crystallization process, and the degree was different for various metal content. With the same range of $y$ axis, height of the first diffraction peak decreased with the addition of metal content, which implied that the crystallinity of the $\mathrm{AlPO}_{4}-5$ was reduced when $\mathrm{Cr}^{3+}$ ions were introduced into the system. The phenomenon is consistent with other metal substituted aluminophosphates. Fig. 1c and d showed the patterns of the integral areas of different peaks $v s$. the crystallization time. It is obviously that the growth rate of (100) and $(102 / 211)$ plane was higher than that of (210) and (002) plane, no matter whether there was metal ion in the gel or not. So CrAPO-5 $(m)$ could remain similar hexagonal prisms as that of $\mathrm{AlPO}_{4}-5$.
3.1.2 Isothermal experiments: analysis of crystallization kinetics. In all isothermal experiments, the sample was heated quickly (within $1 \mathrm{~min}$ ) to the desired temperature and kept at that temperature for certain period.

Fig. 2 showed the powder patterns of the CrAPO-5 gels with different $\mathrm{Cr}^{3+}$ content at $150{ }^{\circ} \mathrm{C}$. The Bragg reflections appeared as soon as the gel was introduced into the cells when the molar ratio of $\mathrm{Cr} / \mathrm{P}$ was 0.01 . The time before the appearance of the Bragg reflections, named induction or nucleation time, became longer and longer with the increasing of the $\mathrm{Cr}^{3+}$ ions content in the gels. The nucleation time $t_{0}$, to a certain extent, could present the apparent activation energy for the nucleation process. ${ }^{32}$ With the content of $\mathrm{Cr}^{3+}$ increasing, the nucleation time $t_{0}$ at $150{ }^{\circ} \mathrm{C}$ was prolonged, which indicates the increase of the apparent activation energy for the nucleation process.

Kinetic information on the isothermal crystallization process can be derived from the Avrami-Erofe' $\mathrm{ev}^{47-49}$ expression that is widely used to model phase transitions and crystal growth in solid-state chemistry using the extent of the reaction, $\alpha$, to time $t$ using the relationship

$$
\alpha=1-\exp \left[-\left(k\left(t-t_{0}\right)\right)^{n}\right]
$$

where $t_{0}$ is the induction time, $k$ is the rate constant, and $n$ is the Avrami exponent. The exponent $n$ can be used in most cases to deduce information about the rate of nucleation and the mechanism of nuclei growth. ${ }^{39}$ Common values of $n$ ranges
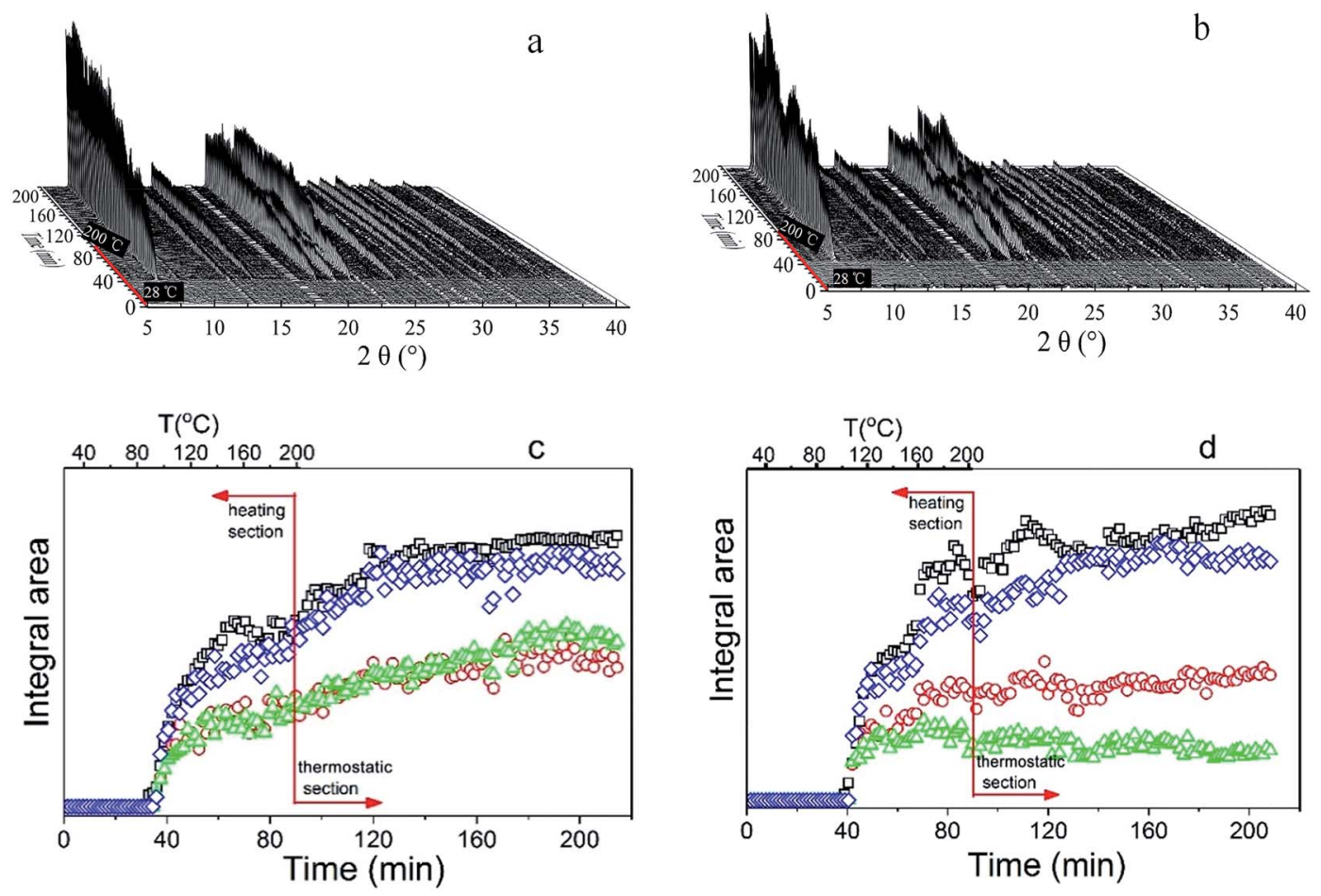

$\square \quad 100 \quad 0 \quad 210 \quad \Delta \quad 002 \quad \diamond \quad 102$ and 211

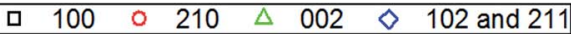

Fig. 1 ( $a$ and b) Stack of powder XRD patterns obtained during the in situ crystallization process when heating the gels from room temperature to $200^{\circ} \mathrm{C}$ : (a) $\mathrm{AlPO}_{4}-5$; (b) $\mathrm{CrAPO}-5(0.05)$; (c and d) patterns of the integral area of different reflection peaks vs. the crystallization time: (c) AlPO $4-5$ and (d) CrAPO-5(0.05). 

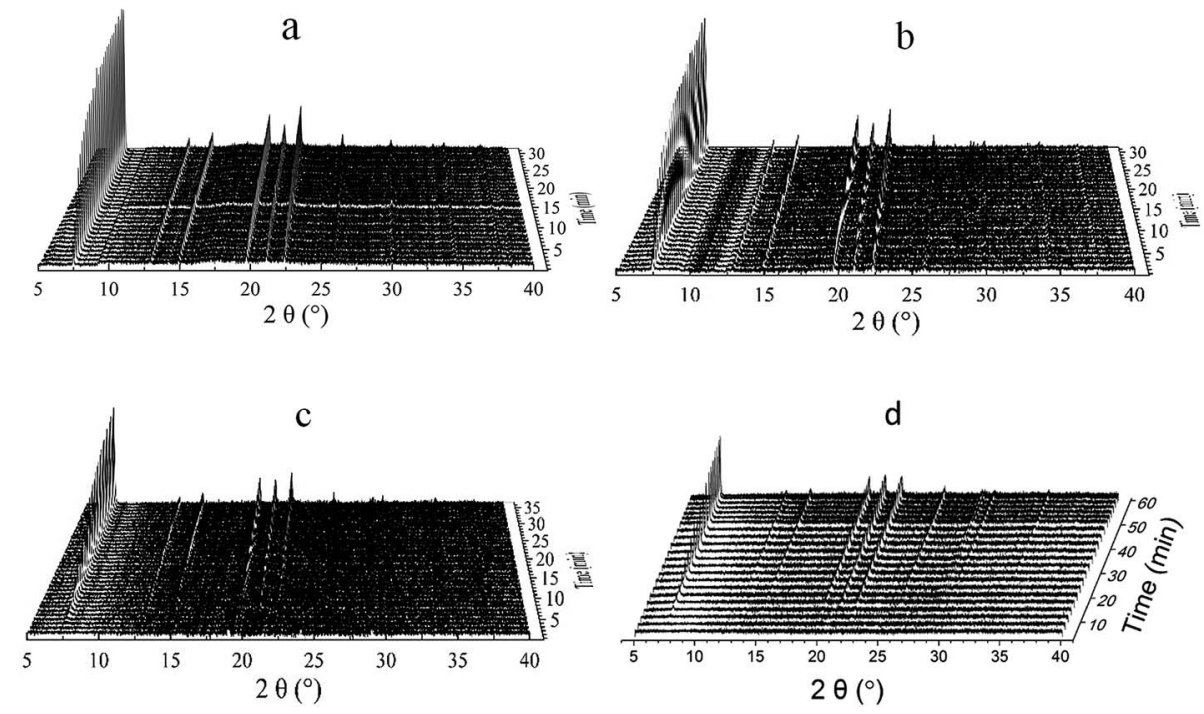

Fig. 2 Stack of powder XRD patterns obtained with $\mathrm{CrAPO}-5(\mathrm{~m})$ when kept at $150{ }^{\circ} \mathrm{C}$ for the duration of the data collection: $(\mathrm{a})$ AlPO $4-5$; (b) CrAPO-5(0.01); (c) CrAPO-5(0.05); (d) CrAPO-5(0.08).

from 0.5 to 4 and contain information both on the dimensionality and the process of crystallization. ${ }^{5}$ Previous work has demonstrated the relevance of this equation in modeling a variety of solid-state reactions but showed that this expression is found to be most applicable in the range $0.15<\alpha<0.8 .^{50,51}$ During the crystallization, a Sharp-Hancock plot $(\ln (-\ln (1-\alpha))$ $v s . \ln (t))$ has been used to obtain the gradient $n$ and intercept $n \ln k^{.52,53}$

The crystallization curves for the isothermal in situ synthesis of $\mathrm{Cr}^{3+}$-substituted aluminophosphates were analyzed in order to extract kinetic information. The evolution of diffraction peak intensity as a function of time can be used to derive valuable information on the kinetics and mechanism involved in the crystallization process. The intensity can be determined by fitting one or several Bragg peaks with a Gaussian function and measuring the corresponding areas that are then converted to the extent of reaction $(\alpha)$, scaled from 0 to 1 , using the relation$\operatorname{ship} \alpha(t)=I_{h k l}(t) / I_{h k l}(\max )$, where $I_{h k l}(t)$ is the integral area of the given peaks at time $t$ and $I_{h k l}(\max )$ is the maximum integral area of these peaks. The sum of four Bragg reflections of 100 ,
210, 002 and 102/211 contributes to each of the peak intensity.

The crystallization curves of CrAPO- 5 with different $\mathrm{Cr}$ ion content were given in Fig. 3a, while the plot of the evolution of the (100) Bragg reflection at half-maximum (FWHM) as a function of temperature was shown in Fig. 3b. The Sharp-Hancock plot has been used to obtain the parameters $n$ and $k$. The obtained plots of the crystallization of $\mathrm{AlPO}_{4}-5$ and CrAPO-5 $(m)$ at $150{ }^{\circ} \mathrm{C}$ presented in Fig. 4a are clearly linear over the whole extent of the data, confirming the validity of the model (outliers due to the occurrence of macroscopic inhomogeneity in the sample during the synthesis were not included in the linear fitting process). The calculated $n$ and $k$ were summarized in Table 2.

When the ratio of $\mathrm{Cr} / \mathrm{P}$ was less than or equal to 0.05 in the gel, the resulting crystallization curves were typical for a crystallization process in aqueous system consisting of an initial period of induction (or nucleation) followed by rapid crystallization of the material and gradual growth of the crystallites until a constant value is reached, which implied the completion
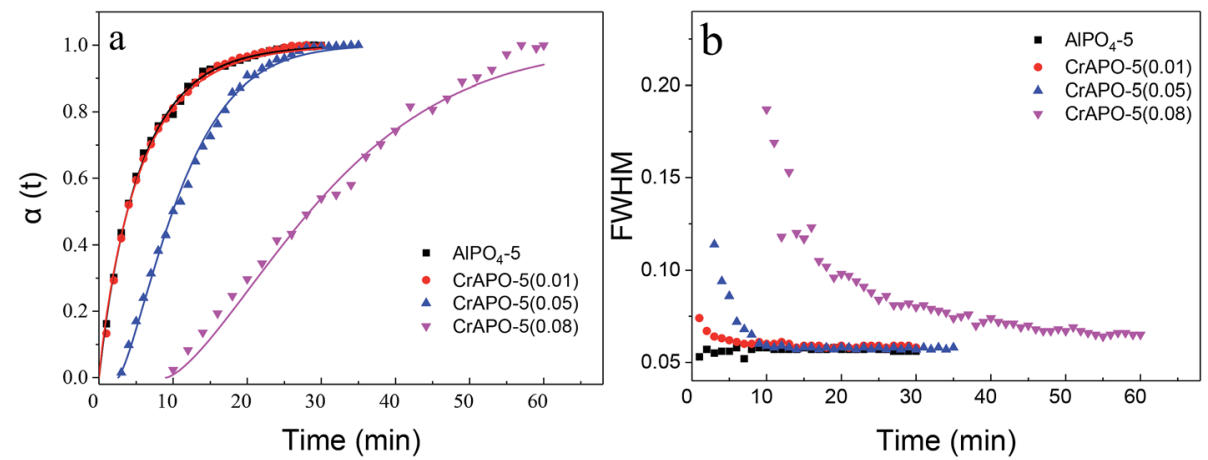

Fig. 3 (a) Crystallization curves extracted from isothermal in situ powder diffraction experiments at $150^{\circ} \mathrm{C}$. Solid curves are the fits to the Avrami expression, eqn (1); (b) the evolution of the experimental full-width at half-maximum (FWHM) of the Bragg reflection of (100). 

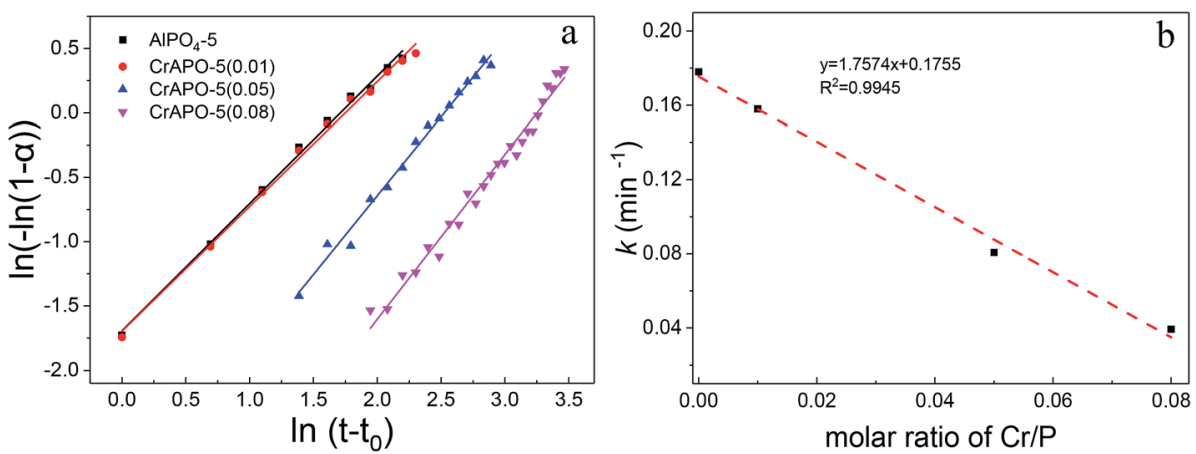

Fig. 4 (a) Sharp-Hancock plots for the formation of $\mathrm{AlPO}_{4}-5$ and $\mathrm{CrAPO}-5(\mathrm{~m})$ plotted data with the range from 0.15 to 0.8 ; $(\mathrm{b})$ the plot of the rate constant $k$ versus the $\mathrm{Cr}$ content in the gel at $150{ }^{\circ} \mathrm{C}$.

of crystal growth. The results are similar to that of $\mathrm{Me}^{2+}$ substituted microporous aluminophosphates in aqueous system..$^{32,34,36,38,41}$ The fitting curves using the $n, k$ parameters calculated from the Sharp-Hancock plots showed highly consistent with the experimental crystallization curves. The Avrami exponent $n$ of CrAPO-5 obtained from the Sharp-Hancock plots was larger than that of $\mathrm{AlPO}_{4}-5$, and the rate constant $k$ was smaller than that of $\mathrm{AlPO}_{4}-5$, as shown in Table 2. These results illustrate that the nuclei growth and crystallization were both retarded in the presence of $\mathrm{Cr}$ ions. And the inhibitory effect became stronger and stronger with the increase of metal content in the gel. When the mole ratio of $\mathrm{Cr} / \mathrm{P}$ was 0.01 , the crystallization curve was almost overlapped by that of $\mathrm{AlPO}_{4}-5$. The obtained $n$ for different $\mathrm{Cr}^{3+}$ content was in the range of 1.0 to 1.3 , which showed little variation with $\mathrm{Cr}^{3+}$ content. We conclude that the growth mechanism of CrAPO-5 with different $\mathrm{Cr}^{3+}$ content was similar to that of $\mathrm{AlPO}_{4}-5$ and was independent with the $\mathrm{Cr}$ content within the studied range.

The FWHM, as manifested in Fig. 3b, was used to determine the variation in crystallite size with $\mathrm{Cr}^{3+}$ content. The FWHM values for all systems decreases sharply with the rate at which the decline takes place dependent upon the reaction temperature except $\mathrm{AlPO}_{4}-5$, which was at a rather high level at first and remained nearly unchanged later. It is interesting that the FWHM decreases to almost the same value within the study

Table 2 Kinetic data for crystallization of $\mathrm{AlPO}_{4}-5$ and $\mathrm{CrAPO}-5$

\begin{tabular}{llllll}
\hline Crystalline gel & $T\left({ }^{\circ} \mathrm{C}\right)$ & $n$ & $k\left(\mathrm{~min}^{-1}\right)$ & $t_{0}(\mathrm{~min})$ & $E_{\mathrm{a}}\left(\mathrm{kJ} \mathrm{mol}^{-1}\right)$ \\
\hline AlPO $_{4}-5$ & 140.1 & 1.0 & 0.121 & 1.4 & 48.7 \\
& 144.9 & 1.1 & 0.134 & 0.7 & \\
CrAPO-5(0.01) & 149.7 & 1.1 & 0.167 & 0.6 & \\
& 140.1 & 1.0 & 0.111 & 7.2 & 53.5 \\
& 144.9 & 1.1 & 0.142 & 4.3 & \\
CrAPO-5(0.05) & 149.7 & 1.1 & 0.158 & 0.5 & \\
& 140.1 & 1.1 & 0.0533 & 12.7 & 62.7 \\
CrAPO-5(0.08) & 144.9 & 1.2 & 0.0757 & 5.3 & \\
& 149.7 & 1.3 & 0.0813 & 4.1 & \\
& 150.9 & 1.1 & 0.0383 & 10.7 & 65.7 \\
& 158.2 & 1.1 & 0.0434 & 8.6 &
\end{tabular}

range. The phenomena was inconsistent with the observation with SEM results observed in ex situ studies, from which the particle size can be obtained. The size calculated from XRD spectra was crystallite size, while the particles observed in SEM picture was the aggregates of those small crystallites. The aggregating degree was different for CrAPO-5 with different chromium content, so the particle size calculated from SEM pictures was different.

The rate constants $k$ for different crystallization process showed a perfect linear relationship with the molar ratio of $\mathrm{Cr} / \mathrm{P}$ in the gel, as shown in Fig. 4b. It is generally accepted that as $n$ becomes larger, the rate of formation of nucleation sites becomes increasingly important in determining the overall rate of crystallization. Similar to the crystallization of CoAPO- $5,{ }^{5}$ for CrAPO-5 the higher value of $n$ parameter of $c a$. 1.3 indicates the following possible mechanism: CrAPO-5 crystallized with the same 1D mechanism as pure $\mathrm{AlPO}_{4}-5$ but the presence of chromium slowed down the nucleation and crystallization rate severely. The prolonged induction time and decreased $k$ constant indicate that the inhibitory effect for both the two stages is proportional to the Cr ions content in the synthesis gels.

Fig. 5a-d exhibited the observed and calculated crystallization curves at different temperature, whereas the plot of the evolution of FWHM of the (100) Bragg reflection as a function of time is shown in Fig. 5e-h. It is consistent with former works that the crystallization rate was proportional to the temperature. Furthermore, the growth profiles for each phase showed little variation with temperature, which we conclude is the evidence that the growth mechanism is not temperature-dependent for the range of temperatures studied. As described above, the FWHM decreased very sharply up to a point that coincided approximately with the change in rate of the reaction and remained effectively constant until the extent of the reaction reaches $\alpha$ maximum observed in Fig. 5a-d. The sharp variations of FWHM during the crystallite growth were larger for CrAPO-5 than that for $\mathrm{AlPO}_{4}-5$, which was also observed in the crystallization process of CoAPO-5. ${ }^{5}$ Furthermore, the reduction became larger when the experimental temperature decreased. As has been proved in laboratory experiment that lower crystalline temperature is benefit for the formation of smaller crystals. The 

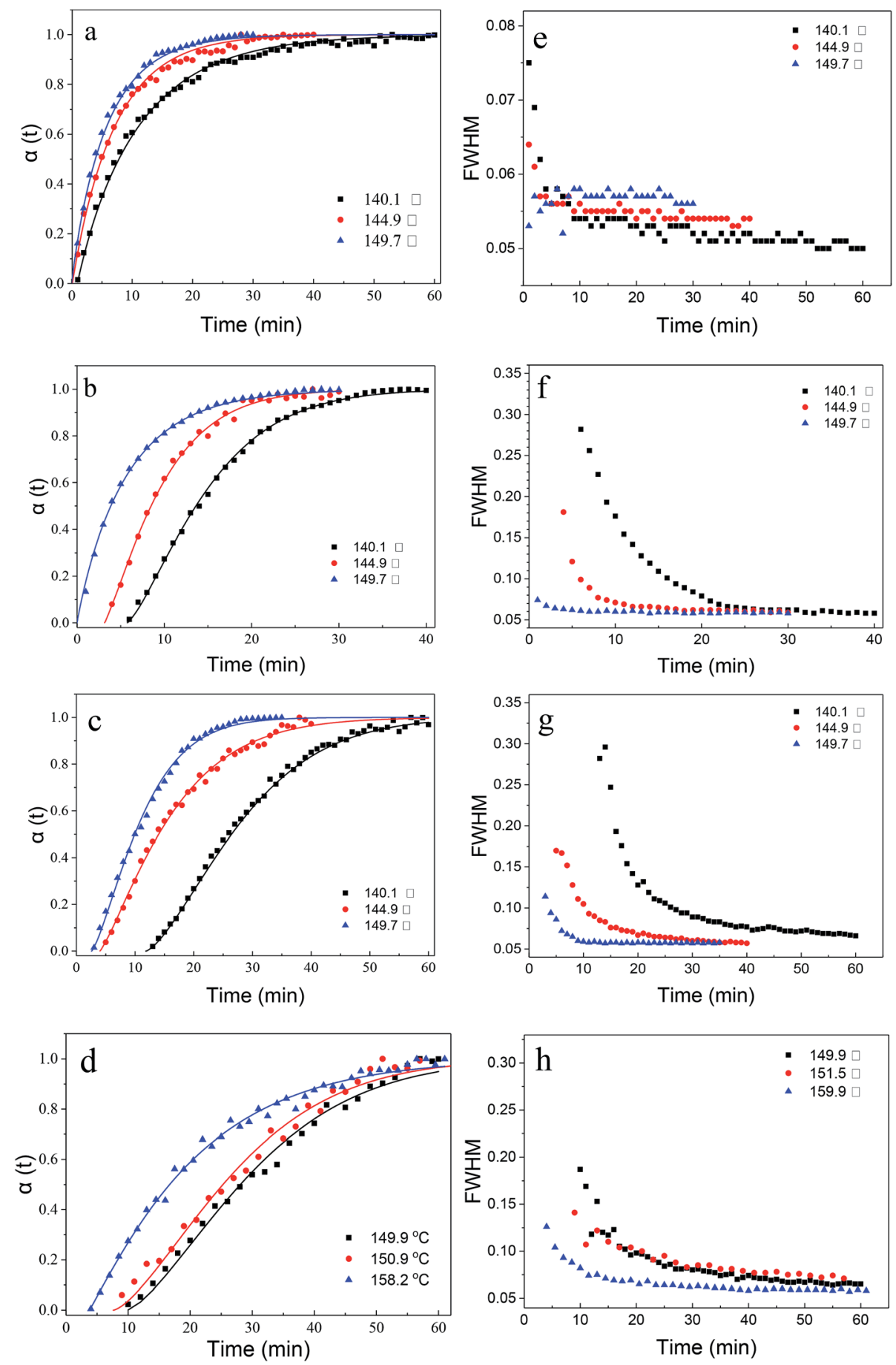

Fig. 5 (a-d) Crystallization curves extracted from isothermal in situ powder diffraction experiments at temperatures between 140 and $160{ }^{\circ} \mathrm{C}$. Solid curves are the fits to the Avrami expression, eqn (1); and (e-h) the evolution of the experimental full-width at half-maximum (FWHM) of the Bragg reflection of (100). (a and e) $\mathrm{AlPO}_{4}-5$, (b and f) CrAPO-5(0.01), and (c and g) CrAPO-5(0.05), (d and h) CrAPO-5(0.08).

crystal size has relation to the FWHM to some extent, that is to say, the smaller the crystal size is, the larger the FWHM will be. The changes observed in the in situ experiments gave similar trend.

The general Arrhenius expression, $k=A \exp \left(-E_{\mathrm{a}} / R T\right)$, was used for the extraction of apparent activation energies for the crystal growth (see Fig. 6a and Table 2). As expected, the apparent activation energy for the crystal growth increased significantly with the introduction of $\mathrm{Cr}$ ions into pure $\mathrm{AlPO}_{4}-5$. It had a fair linear relationships between the apparent activation energy and the content of $\mathrm{Cr}^{3+}$ ions in the scope of the study. The increased apparent activation energy reflect the increasing difficulty for the prepared gels to crystallize. 

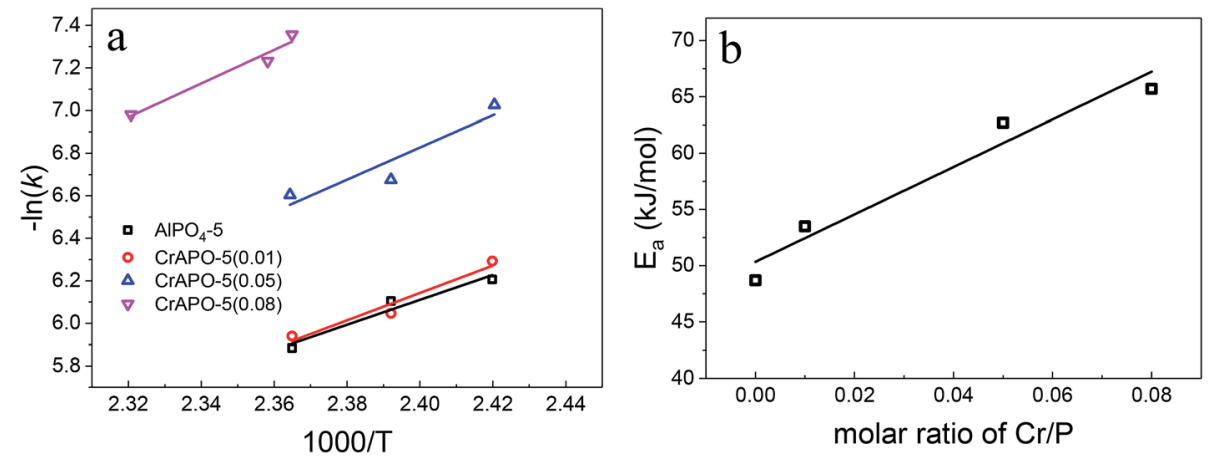

Fig. 6 (a) Arrhenius plots for determination of activation energies for the crystallization of CrAPO-5 at different temperature; (b) the plot of the apparent activation energy $E_{\mathrm{a}}$ of crystal growth versus the molar ratio of $\mathrm{Cr} / \mathrm{P}$ in the gel.

3.1.3 Isothermal experiments: analysis of the crystal structure parameters. We analyzed the HRXRD data in detail to extract the unit cell parameters and crystallite sizes of each crystalline AFI phase employing a fundamental parameter approach using Jade 6.5 with the initial unit cell parameters taken from the PDF card of \#39-0216 $(a(=b)=13.713 \AA$, $c=$ $8.427 \AA, \alpha(=\beta)=90^{\circ}, \gamma=120^{\circ}$ and space group P6cc). Interesting additional information on the structural aspects during the growth process was yielded from the results. From this study, considering the peak at degrees, average particle size has been estimated by using Debye-Scherrer formula. ${ }^{54-56}$

$$
D=K \lambda / \beta \cos \theta
$$

where ' $K$ ' is a dimensionless shape factor, with a value close to unity. The shape factor has a typical value of about 0.89 , ' $\lambda$ ' is the wavelength of X-ray $(0.154 \mathrm{~nm})$, ' $\beta$ ' is the FWHM (full width at half maximum), ' $\theta$ ' is the diffraction angle and ' $D$ ' is particle diameter size. Because all of the crystallization cells used in the in situ experiment were not exactly the same and the peak position was not corrected, so the comparison between each experiments were not exactly reliable, but the change during one crystallization process could be fully trustable. The calculated particle size details are shown in Fig. 7. Results show that

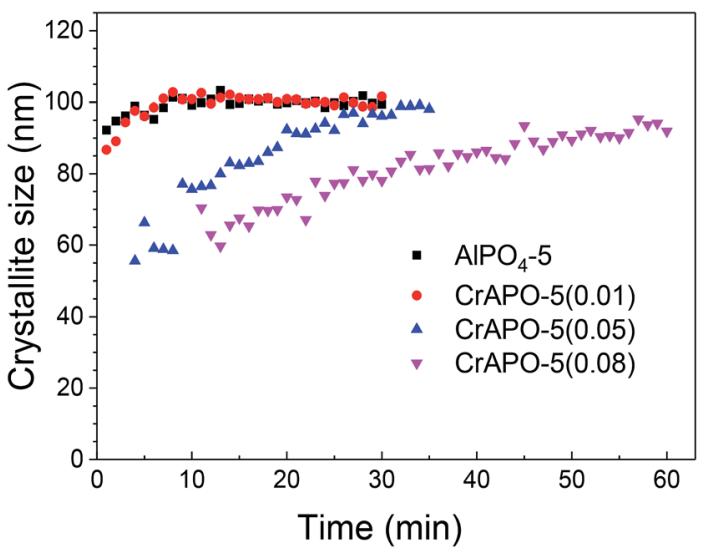

Fig. 7 The variation in the grain size of the AFI crystals plotted against crystallization time.
$\mathrm{Cr}^{3+}$-substituted aluminophosphate molecular sieves undergone very different changes during the crystallization compared with pure $\mathrm{AlPO}_{4}-5$ and $\mathrm{Co}^{2+}$ - or $\mathrm{Zn}^{2+}$-substituted ones. ${ }^{41}$ The crystallite size of $\mathrm{AlPO}_{4}-5$ ranged between about 90-105 nm, and grew by approximately $14 \%$ during the hydrothermal crystallization. CrAPO-5(0.01) showed similar changes in the crystallite size during the hydrothermal crystallization, but with larger starting initial particle size. When the $\mathrm{Cr}^{3+}$ content increased, in other words, when the molar ratio of $\mathrm{Cr} / \mathrm{P}$ was equal to or greater than 0.05 , the hydrothermal crystallization displayed very different variation. The crystallite size ranged from about $50 \mathrm{~nm}$ at the beginning, and grew to almost the same level compared with $\mathrm{AlPO}_{4}-5$ and CrAPO-5(0.01), which gave about $50 \%$ growth during the hydrothermal crystallization. The introduction of $\mathrm{Cr}^{3+}$ might resulted in different crystallization mechanism compared with $\mathrm{Co}^{2+}$ - or $\mathrm{Zn}^{2+}$-substituted aluminophosphate molecular sieves. ${ }^{\mathbf{4 1}}$ The considerable higher changes in the grain size of CrAPO-5 might relate to the interaction between $\mathrm{Cr}^{3+}$ ions and the framework, which resulted in the trap of $\mathrm{Cr}^{3+}$ into the $\mathrm{AlPO}_{4}-5$ framework after the build-up of microporous structure.

The plots of the $a(=b)$ and $c$ parameters over crystallization time including the cell volume at $150{ }^{\circ} \mathrm{C}$ were shown in Fig. 8 . The $a(=b)$ parameter remained nearly constant with a little decrease during the crystallization process and was found to increase with $\mathrm{Cr}^{3+}$ content. The values are 13.765 $\AA$ (CrAPO5(0.01)), $13.816 \AA$ (CrAPO-5(0.05)) and 13.817 (CrAPO-5(0.08)). The value was larger than that of $\mathrm{Co}^{2+}$ - or $\mathrm{Zn}^{2+}$-substituted aluminophosphates. ${ }^{41}$ Compared to un-substituted $\mathrm{AlPO}_{4}-5,13.716$ $\AA$, the greater $a(=b)$ parameters indicated that the metal ions was part of the framework, which could result in the lattice expansion. Furthermore, the lattice expansion was limited, which might relate to the amount of $\mathrm{Cr}^{3+}$ interacted with the framework was limited. It is to say that there is a highest amount of metal ions that could interact with the framework $\mathrm{P}$ atoms. The redundant metal ions are located in other extra-framework sites which have little influence to the structure change of the crystals. Octahedral coordinated $\mathrm{Cr}^{3+}$ cation has larger ionic radii, 0.615 $\AA$, compared to $\mathrm{Co}(\mathrm{II}), \mathrm{Zn}$ (II) and $\mathrm{Al}(\mathrm{III})$ which have the ionic radii of $0.58 \AA$, $0.60 \AA$ and $0.39 \AA$, respectively, ${ }^{57,58}$ therefore the larger 

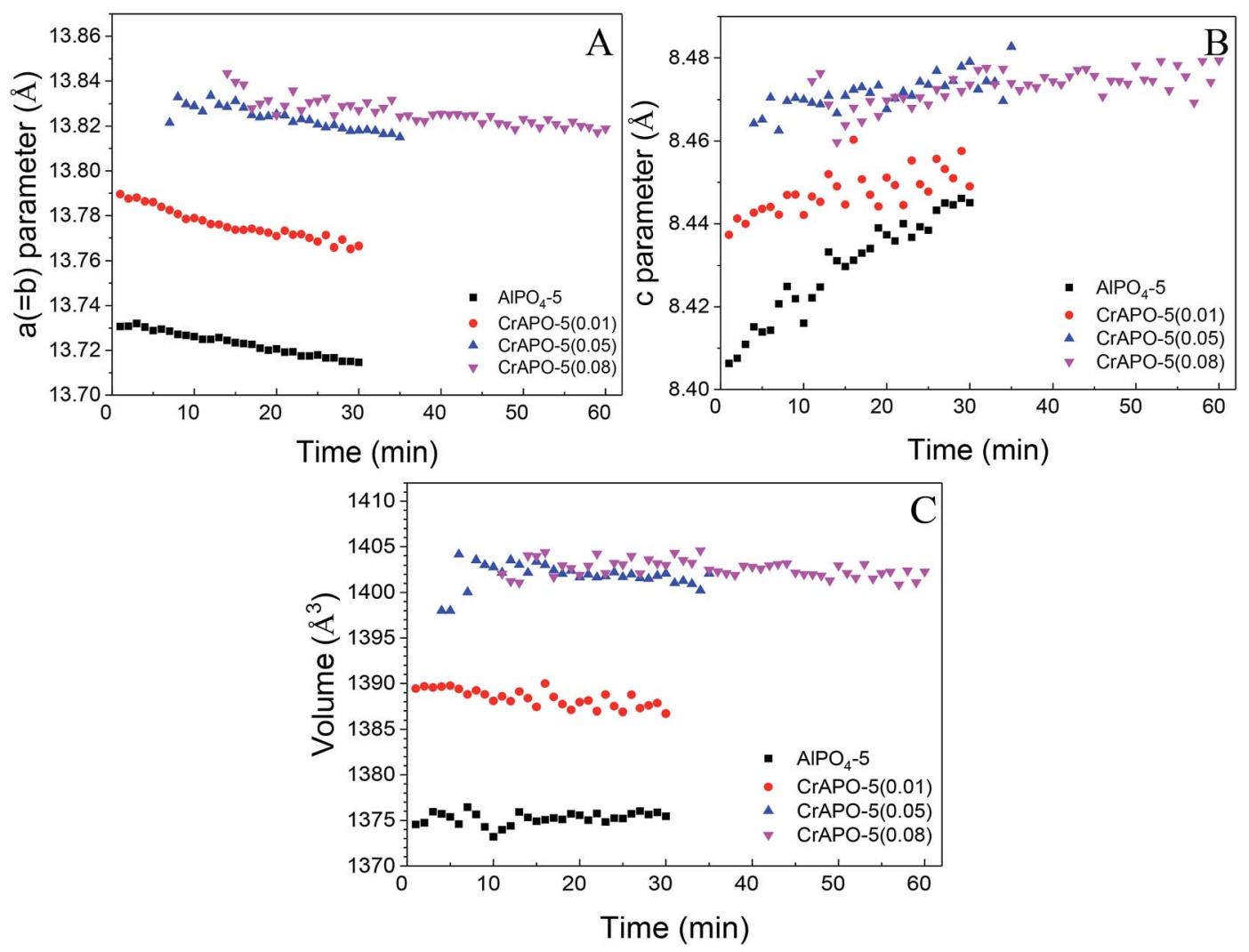

Fig. 8 Variation in the lattice parameters obtained from HRXRD data recorded at the 4B9A (BSRF) beamline, as a function of time during the crystallization process; $(A)$ shows a $(=b)$ parameter change, $(B)$ is the $c$ parameter variation and $(C)$ is the change in the cell volume over crystallization time. The analysis was performed only on data when the peak reflections were observed obviously.

expansion in the $a(=b)$ direction is observed when a metal ion is trapped into the framework.

The change trend of $c$ parameter is in contrast to that of $a(=b)$ parameter. The $c$ parameter was found to increase over crystallization time, more predominantly for un-substituted $\mathrm{AlPO}_{4}-5$ (by approximately 0.04 Å) compared to CrAPO-5 (increase of $0.01 \AA$ ). The increase in $c$ parameter during the crystallization process could be ascribed to the uptake of water molecular and the template orientation, as explained by Sankar. ${ }^{41}$ The increase in the $c$ parameter, over the crystallization time, was due to the uptake of water molecules which may coordinate to $\mathrm{Al}^{3+}$ ions accessible in the channel direction, increasing the $\mathrm{Al}-\mathrm{O}$ bond distance from $1.74 \AA$ for tetrahedral $\mathrm{Al}^{3+}$ up to $1.9 \AA$ for an octahedral environment; the more hydrophilic pure $\mathrm{AlPO}_{4}-5$ (the electronegativity of $\mathrm{Al}^{3+}, \mathrm{Cr}^{3+}$, $\mathrm{Co}^{2+}$, and $\mathrm{Zn}^{2+}$ are $26.72,14.41,9.10$ and 10.38, respectively. ${ }^{59}$ ) should therefore show a larger increase in the $c$ parameter compared to MeAPO-5. On the other hand the template orientation within the structure could also play a role in this change in $c$ parameter and cell volume. From these findings we can conclude that partial of $\mathrm{Cr}^{3+}$ ions in the gel was trapped into the $\mathrm{AlPO}_{4}-5$ framework in such a way as to cause an expansion in the $a(=b)$ direction, which is perpendicular to the channel direction. A change in the $c$ parameter and cell volume illustrates the flexibility of the AFI framework.

\section{Conclusions}

In this study, we have in situ investigated the kinetics and the structural parameters of AFI type CrAPO-5, particularly the variation in lattice constants, with time-resolved HRXRPD during the classical hydrothermal synthesis. Information extracted from the in situ HPXRPD experiment illustrates that the introduction of $\mathrm{Cr}^{3+}$ into pure $\mathrm{AlPO}_{4}-5$ influenced much on the crystallization process not only on the crystallization velocity, but also on the structural parameters. The crystallization was retarded severely by introducing $\mathrm{Cr}$ ions into the $\mathrm{AlPO}_{4}{ }^{-}$ 5 gels. The more the $\mathrm{Cr}^{3+}$ ions was in the gels, the stronger the inhibitory effect was. There was an interesting discovery that linear relationship was existed between the apparent activation energy and the $\mathrm{Cr}^{3+}$ content in the gels. The calculated Avrami exponent $n$ was in the range of 1 to 1.3 , which implied the similar 1D growth mechanism as that of $\mathrm{AlPO}_{4}-5$. The extracted structural parameters showed obviously crystal expansion, which was might be caused by the interaction between the framework P and $\left[\mathrm{Cr}\left(\mathrm{H}_{2} \mathrm{O}\right)_{6}\right]^{3+}$ ions, which need to be further studied.

\section{Conflict of interest}

The authors declare no competing financial interest. 


\section{Acknowledgements}

This work was supported by the National Basic Research Program of China (Grant 21227002), and the Beijing Synchrotron Radiation Facility (BSRF). We are grateful to Prof. Jing Zhang and Prof. Zhonghua Wu (Institute of High-Energy Physics, Chinese Academy of Science) for their helpful discussion on the XAS and XRD data.

\section{References}

1 N. Sheng, Y. Chu, S. Xin, Q. Wang, X. Yi, Z. Feng, X. Meng, X. Liu, F. Deng and F.-S. Xiao, J. Am. Chem. Soc., 2016, 138, 6171-6176.

2 J. Xu, L. Chen, D. Zeng, J. Yang, M. Zhang, C. Ye and F. Deng, J. Phys. Chem. B, 2007, 111, 7105-7113.

3 J. Šponer, J. Čejka, J. Dědeček and B. Wichterlová, Microporous Mesoporous Mater., 2000, 37, 117-127.

4 C. Zenonos, G. Sankar, F. Cora, D. W. Lewis, Q. A. Pankhurst, C. R. A. Catlow and J. M. Thomas, Phys. Chem. Chem. Phys., 2002, 4, 5421-5429.

5 D. Grandjean, A. M. Beale, A. V. Petukhov and B. M. Weckhuysen, J. Am. Chem. Soc., 2005, 127, 1445414465.

6 M. Dong, G. Wang, Z. Qin, J. Wang, T. Liu, Y. Xie and T. Hu, Presented in part at the From Zeolites to Porous MOF Materials - the 40th of International Zeolite Conference, 2007.

7 M. Dong, G. Wang, Z. Qin, J. Wang, T. Liu, S. Yuan and H. Jiao, J. Phys. Chem. A, 2007, 111, 1515-1522.

8 H. K. D. Nguyen, T. N. Don, G. Sankar and R. A. Catlow, Catal. Commun., 2012, 25, 125-129.

9 J. D. Chen, M. J. Haanepen, J. H. C. V. Hooff and R. A. Sheldon, in Stud. Surf. Sci. Catal., Elsevier, 1994, vol. 84, pp. 973-980.

10 R. A. Sheldon, J. D. Chen, J. Dakka and E. Neeleman, in Stud. Surf. Sci. Catal., ed. H. G. K. H. P. J. Weitkamp and W. Hölderich, Elsevier, 1994, vol. 83, pp. 407-416.

11 J. D. Chen, H. E. B. Lempers and R. A. Sheldon, Colloids Surf., A, 1995, 101, 137-146.

12 J. D. Chen and R. A. Sheldon, J. Catal., 1995, 153, 1-8.

13 H. E. B. Lempers and R. A. Sheldon, Appl. Catal., A, 1996, 143, 137-143.

14 A. M. Beale, D. Grandjean, J. Kornatowski, P. Glatzel, F. M. F. D. Groot and B. M. Weckhuysen, J. Phys. Chem. B, 2006, 110, 716-722.

15 B. M. Weckhuysen and R. A. Schoonheydt, Zeolites, 1994, 14, 360-366.

16 B. M. Weckhuysen, I. E. Wachs and R. A. Schoonheydt, Chem. Rev., 1996, 96, 3327-3349.

17 D. Demuth, K. K. Unger, F. Schueth, V. I. Srdanov and G. D. Stucky, J. Phys. Chem., 1995, 99, 479-482.

18 J. P. Lange, A. Gutsze and H. G. Karge, J. Catal., 1988, 114, 136-143.

19 B. Padlyak, J. Kornatowski, G. Zadrozna, K. Fabisiak and A. Gutsze, Mater. Sci., 2005, 23, 1035-1046.

20 D. E. O'Reilly and D. S. MacIver, J. Phys. Chem., 1962, 66, 276281.
21 B. M. Weckhuysen, R. A. Schoonheydt, F. E. Mabbs and D. Collison, J. Chem. Soc., Faraday Trans., 1996, 92, 24312436.

22 Z. Zhu, T. Wasowicz and L. Kevan, J. Phys. Chem. B, 1997, 101, 10763-10768.

23 Z. Zhu and L. Kevan, Phys. Chem. Chem. Phys., 1999, 1, 199206.

24 B. V. Padlyak, J. Kornatowski, G. Zadrozna, M. Rozwadowski and A. Gutsze, J. Phys. Chem. A, 2000, 104, 11837-11843.

25 A. Grave, Masteroppgave Master's thesis, Norwegian University of Science and Technology, Faculty of Natural Sciences and Technology, 2009.

26 E. Groppo, C. Prestipino, F. Cesano, S. Bonino, C. Lamberti, P. C. Thüne, J. W. Niemantsverdriet and A. Zecchina, J. Catal., 2005, 230, 98-108.

27 D. Park, Y.-S. Yun and J. M. Park, J. Colloid Interface Sci., 2008, 317, 54-61.

28 J. Kornatowski, B. Wichterlová, M. Rozwadowski and W. H. Baur, in Stud. Surf. Sci. Catal., ed. H. G. K. H. P. J. Weitkamp and W. Hölderich, Elsevier, 1994, vol. 84, pp. 117-124.

29 P. Norby, Curr. Opin. Colloid Interface Sci., 2006, 11, 118-125. 30 R. J. Francis, S. O'Brien, A. M. Fogg, P. S. Halasyamani, D. O'Hare, T. Loiseau and G. Férey, J. Am. Chem. Soc., 1999, 121, 1002-1015.

31 A. N. Christensen, P. Norby and J. C. Hanson, Acta Chem. Scand., 1997, 51, 249-258.

32 A. N. Christensen, T. R. Jensen, P. Norby and J. C. Hanson, Chem. Mater., 1998, 10, 1688-1693.

33 P. Norby, A. Nørlund Christensen and J. C. Hanson, Stud. Surf. Sci. Catal., 1994, 84, 179-186.

34 P. Norby and J. C. Hanson, Catal. Today, 1998, 39, 301-309. 35 A. T. Davies, G. Sankar, C. R. A. Catlow and S. M. Clark, J. Phys. Chem. B, 1997, 101, 10115-10120.

36 K. Simmance, G. Sankar, R. G. Bell, C. Prestipino and W. V. Beek, Phys. Chem. Chem. Phys., 2010, 12, 559-562.

37 G. Sankar, J. M. Thornas, F. Reya and G. N. Greavesb, J. Chem. Soc., Chem. Commun., 1995, 2549-2550.

38 A. N. Christensen, P. Norby and J. C. Hanson, Microporous Mesoporous Mater., 1998, 20, 349-354.

39 P. Norby, A. N. Christensen and J. Hanson, Inorg. Chem., 1999, 38, 1216-1221.

40 M. G. O'Brien, M. Sanchez-Sanchez, A. M. Beale, D. W. Lewis, G. Sankar and C. R. A. Catlow, J. Phys. Chem. C, 2007, 111, 16951-16961.

41 K. Simmance, W. V. Beek and G. Sankar, Faraday Discuss., 2015, 177, 237-247.

42 M. M. J. Treacy and J. B. Higgins, Collection of Simulated XRD Powder Patterns for Zeolites, 2001.

43 P. Sheng, Doctor's thesis, Chinese Academy of Sciences, Institute of Coal Chemistry, 2017.

44 A. Bergamaschi, A. Cervellino, R. Dinapoli, F. Gozzo, B. Henrich, I. Johnson, P. Kraft, A. Mozzanica, B. Schmitt and X. Shi, J. Synchrotron Radiat., 2010, 17, 653-668.

45 R. Du, Q. Cai, Z. Chen, G. Yu, H. Liu and Z. Wu, Instrum. Sci. Technol., 2015, 1-11, DOI: 10.1080/10739149.2015.1060608. 
46 R. Du, Z. Chen, Q. Cai, J. Fu, Y. Gong and Z. Wu, Chin. Phys. C, 2015, 7, 677011.

47 M. Avrami, J. Chem. Phys., 1939, 7, 1103-1112.

48 M. Avrami, J. Chem. Phys., 1940, 8, 212-224.

49 M. Avrami, J. Chem. Phys., 1941, 9, 177-184.

50 A. M. Fogg, S. J. Price, R. J. Francis, S. O'Brien and D. O'Hare, J. Mater. Chem., 2000, 10, 2355-2357.

51 A. M. Beale, G. Sankar, C. R. A. Catlow, P. A. Anderson and T. L. Green, Phys. Chem. Chem. Phys., 2005, 7, 1856.

52 J. D. Hancock and J. H. Sharp, J. Am. Ceram. Soc., 1972, 55, 74-77.

53 M. Milanesio, G. Artioli, A. F. Gualtieri, L. Palin and C. Lamberti, J. Am. Chem. Soc., 2003, 125, 14549-14558.
54 B. D. Cullity, Elements of X-Ray Diffraction, Addison-Wesley Company, U. S. A., 1956.

55 R. John and S. S. Florence, Chalcogenide Lett., 2010, 7, 269273.

56 R. John and S. S. Florence, Chalcogenide Lett., 2009, 6, 535539.

57 R. D. Shannon and C. T. Prewitt, Acta Crystallogr., Sect. B: Struct. Crystallogr. Cryst. Chem., 1969, 25, 925-946.

58 R. D. Shannon, Acta Crystallogr., Sect. A: Cryst. Phys., Diffr., Theor. Gen. Crystallogr., 1976, 32, 751-767.

59 Y. Feng, B. Zhang, L. Xuan and Y. Zhu, J. Dalian Inst. Light Ind., 1998, 17, 70-76. 